\title{
Correction to: Deep mantle melting, global water circulation and its implications for the stability of the ocean mass
}

Shun-ichiro Karato ${ }^{1 *}$, Bijaya Karki ${ }^{2}$ and Jeffrey Park ${ }^{1}$

Correction to: Prog Earth Planet Sci 7, 76 (2020)

https://doi.org/10.1186/s40645-020-00379-3

Following publication of the original article (Karato et al., 2020), the author identified there is a minor typo in Fig. 13 and graphical abstract image. The correct Fig. 13 and graphic abstract image are provided below. The original paper has been updated.

\footnotetext{
The original article can be found online at https://doi.org/10.1186/s40645020-00379-3.

* Correspondence: shun-ichiro.karato@yale.edu

'Department of Earth and Planetary Sciences, Yale University, New Haven, CT 06520, USA

Full list of author information is available at the end of the article
}

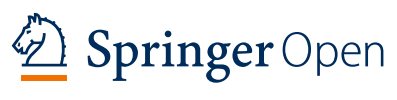

(c) The Author(s). 2021 Open Access This article is licensed under a Creative Commons Attribution 4.0 International License, which permits use, sharing, adaptation, distribution and reproduction in any medium or format, as long as you give appropriate credit to the original author(s) and the source, provide a link to the Creative Commons licence, and indicate if changes were made. The images or other third party material in this article are included in the article's Creative Commons licence, unless indicated otherwise in a credit line to the material. If material is not included in the article's Creative Commons licence and your intended use is not permitted by statutory regulation or exceeds the permitted use, you will need to obtain permission directly from the copyright holder. To view a copy of this licence, visit http://creativecommons.org/licenses/by/4.0/. 

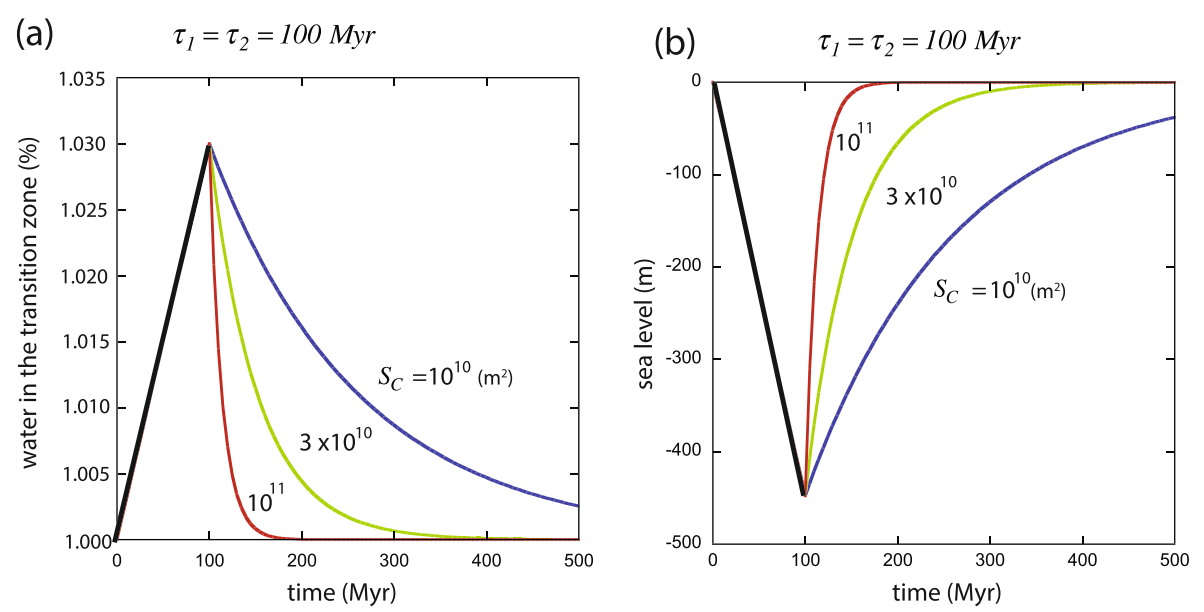

(c) $\quad \tau_{1}=100 \mathrm{Myr}, \tau_{2}=200 \mathrm{Myr}$

(d) $\quad \tau_{1}=100 \mathrm{Myr}, \tau_{2}=200 \mathrm{Myr}$
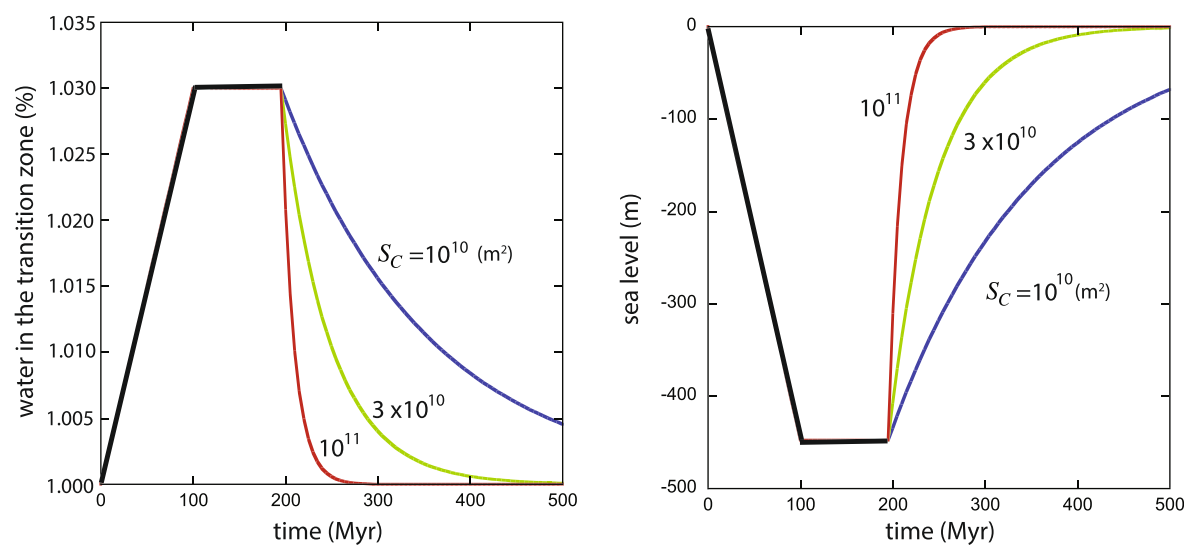

Fig. 13 Results of model calculations on ocean mass history. Regassing parameters (rate of regassing and duration of regassing pulse $\left.\left(\tau_{1}\right)\right)$ are chosen to reproduce the inferred rapid sea-level drop (2-3 m/Myrs (in the last 100 Myrs); Fig. 6). Degassing parameters include the area of cool regions with excess degassing $\left(S_{C}\right)$ and the delay time $\left(\tau_{2}\right)$ for degassing since the beginning of excess regassing (and the plume upwelling velocity $\left(\sim 1 \mathrm{~m} /\right.$ year)). a History of the water content in the MTZ $\left(\tau_{1}=\tau_{2}=100 \mathrm{Myrs}\right)$. b Sea-level change corresponding to the model shown in (a)

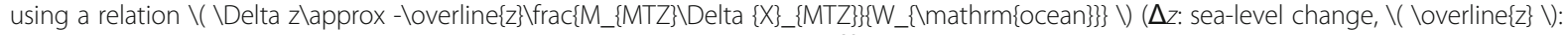
average depth of the oceans $(=3730 \mathrm{~m}), M_{\text {MTz: }}$ mass of the MTZ $\left.\left(=4 \times 10^{23} \mathrm{~kg}\right)\right), \Delta X_{\text {MTZ: }}$ change in the water content of the MTZ; $W_{\text {ocean: }}$ mass of oceans $\left(=1.4 \times 10^{21} \mathrm{~kg}\right)$ ). b Same as (a) except that $\tau_{1}=100$ Myrs, and $\tau_{2}=200$ Myrs. c Same as (b) except that $\tau_{1}=100$ Myrs, and $\tau_{2}=200$ Myrs. Observed sea-level changes (Fig. 7) can be explained with $S_{C}=(3-10) \times 10^{10}\left(\mathrm{~m}^{2}\right)$ (i.e., a region with 200-350 km diameter) 

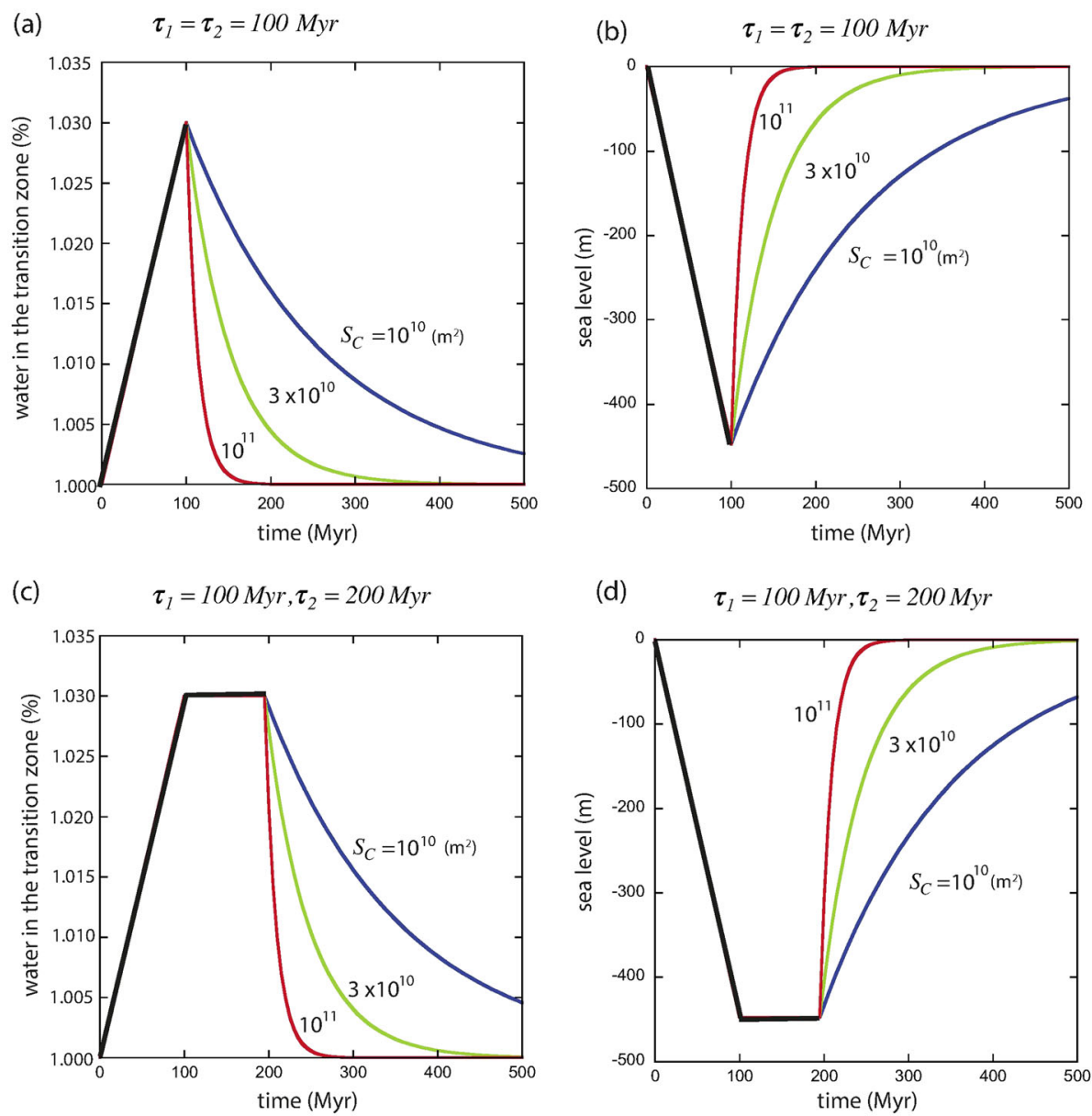

\section{Author details}

'Department of Earth and Planetary Sciences, Yale University, New Haven, CT

06520, USA. ${ }^{2}$ School of Electrical Engineering and Computer Science,

Department of Geology and Geophysics, Center for Computation and

Technology, Louisiana State University, Baton Rouge, LA 70803, USA.

Published online: 27 January 2021

\section{Reference}

Karato et al. (2020) Deep mantle melting, global water circulation and its

implications for the stability of the ocean mass. Prog Earth Planet Sci 7:76

https://doi.org/10.1186/s40645-020-00379-3 